\title{
Conduta ética dos pesquisadores em contabilidade: diferenças entre a crença e a práxis
}

\section{Ethical conduct of accounting researchers : differences between belief and praxis}

\author{
Maria Thereza Pompa Antunes \\ Professora Doutora do Programa de Pós-Graduação em Ciências Contábeis do Centro de Ciências Sociais e Aplicadas da Universidade \\ Presbiteriana Mackenzie \\ E-mail: mariathereza@mackenzie.br \\ Octavio Ribeiro de Mendonça Neto \\ Professor Doutor do Programa de Pós-Graduação em Ciências Contábeis do Centro de Ciências Sociais e Aplicadas da Universidade \\ Presbiteriana Mackenzie \\ E-mail: octavio.mendonca@mackenzie.br
}

José Carlos Tiomatsu Oyadomari

Professor Doutor do Programa de Pós-Graduação em Ciências Contábeis do Centro de Ciências Sociais e Aplicadas da Universidade Presbiteriana Mackenzie

E-mail: oyadomari@mackenzie.br

Rodrigo Takashi Okimura

Professor Doutor do Centro de Ciências Sociais e Aplicadas da Universidade Presbiteriana Mackenzie

E-mail: rodrigo.okimura@gmail.com

Recebido em 03.06.2011 - Aceito em 13.07.2011 - $2^{a}$. versão aceita em 19.11.2011

\section{RESUMO}

Este estudo aborda a questão da ética nas pesquisas científicas em contabilidade e tem por objetivo principal compreender como os acadêmicos de contabilidade percebem as questões éticas em três dimensões: a) Questões éticas relacionadas com o processo de pesquisa; B) Questões éticas referentes a relação entre orientador e orientando e C) Questões éticas entre pares no desenvolvimento de pesquisas conjuntas e na divulgação dos seus resultados. Para tanto, foi desenvolvido um questionário baseado em: Gustafsson et al. 1984; Creswell (2003); Needles, Jr., (2008); Miyazaki e Taylor (2008) e Leite et al. (2010). Do total de questionários enviados (218), 56 foram devolvidos, o que representa $26 \%$ da população de 218 professores permanentes dos 18 programas de pós-graduação brasileiros de contabilidade. No geral, os resultados sugerem que todas as questões propostas no questionário foram consideradas como valores éticos de extrema importância na percepção dos entrevistados. A análise pareada dos dados sugere que alguns valores que são considerados importantes pelos respondentes não são praticados por eles na mesma intensidade; enquanto outros que não são considerados como de extrema importância são intensamente praticados e não se podem ignorar essas diferenças. Em sínstese, com base no conceito de Foucault sobre a "relação consigo mesmo" (FOUCAULT, 1984), considera-se que os resultados deste estudo merecem uma reflexão cuidadosa por parte dos acadêmicos, a fim de aprimorarem o seu comportamento ético, uma vez que isso reflete o consenso do comportamento moral de uma amostra significativa dos pesquisadores brasileiros em contabilidade.

Palavras-chave: Ética. Pesquisa contábil. Foucault.

\section{ABSTRACT}

This study addressed the issue of ethics in scientific accounting research. The primary aim was to understand how accounting researchers perceive ethical issues in three dimensions: A) Ethical issues related with the 
scientific research process; B) Ethical issues about the relation between supervisor and researcher and C) Ethical issues among peers in the development of joint research and in the dissemination of results. For this purpose, a questionnaire was developed based on Gustafsson et al. 1984; Creswell (2003), Needles, Jr., (2008), Miyazaki and Taylor (2008) and Leite et al. (2010). A total of 56 questionnaires were returned, which represents $26 \%$ of the population of 218 permanent professors affiliated with the 18 Brazilian graduate programs in accounting. Overall, our findings suggest that all issues proposed in the questionnaire were considered ethical values of extreme importance in the respondents' perception. Additionally, these results also suggest that they do not practice some values they considered important with the same intensity, while other values that are not regarded as extremely important are intensely practiced, and we cannot disregard these differences. Finally, based on the Foucault's concept of the relationship with the self (FOUCAULT, 1984), we think that researchers should carefully consider the results of this study in order to hone their ethical behavior, as this reflects the consensus on moral behavior in a significant sample of Brazilian accounting researchers.

Keywords: Ethics. Accounting research. Foucault.

\section{INTRODUÇÃO}

O estudo do comportamento ético do profissional da contabilidade tem sido, nos últimos anos, um tema recorrente nas pesquisas acadêmicas em nível nacional e internacional como se pode verificar em Alves, Lisboa, Weffort \& Antunes (2007); Cardoso, De Souza \& Almeida (2006); Pires, Ott \& Damacena (2009); Cardoso (2006) e Borges \& Medeiros (2007) e Armstrong (1993), Leung \& Cooper (1994); Jeffrey \& Weatherholt (1996); Cohen (1995); Gul, Ng \& Tong (2003); Hilttebel \& Jones (1992); Mintz (1995); Green \& Weber (1997); Mele (2005); Finn, Chonko \& Hunt (1988), Shearer (2002); Brown, Mendenhall \& Khamer (2003); Tsui (1996); Goodwin, Goodwin \& Filler (2000); Ho \& Lin (2008); St Pierre, Nelson \& Gabbin (1990), Shaub (1994); Thorne \& Magnan (2003); Yayla \& Demir (2009) e Uysal (2009).

Esses estudos foram realizados com diversas abordagens e se justificam, principalmente, devido ao fato de o tema 'Ética' suscitar a preocupação da sociedade com as relevantes implicações morais, econômicas e sociais das informações geradas por esses profissionais. Todavia, em relação aos aspectos éticos que envolvem o processo de pesquisa em Contabilidade, ou seja, na geração e disseminação do conhecimento contábil, a literatura não é tão abundante.
No Brasil e também em nível internacional, a maior parte do conhecimento contábil é gerada e disseminada nos programas de pós-graduação que, segundo Peleias, Wahlmann, Parisi \& Antunes (2010), foram criados para formar docentes e pesquisadores de alto nível.

Ao acadêmico que atua em programas de pós-graduação stricto sensu, orientando dissertações e teses e/ou desenvolvendo suas pesquisas, lhe é imposta uma grande responsabilidade. Essa responsabilidade deriva do rigor da aplicação do método científico e da condução da orientação, bem como da forma de divulgação do conhecimento gerado. Entende-se que a conduta ética adequada, nesse processo, está no mesmo nível de exigência do conhecimento específico que lhe é requerido.

De fato, é incontestável que o desenvolvimento do conhecimento científico requer rigor metodológico e, para tanto, existem inúmeros livros e manuais que se propõem a aprimorar esse processo. Dentre esses, alguns abordam as questões que envolvem a ética na pesquisa, conforme se pode verificar em: Creswell (2003); Collins \& Hussey (2009); Appolinário (2007); Booth; Colonb \& Williams (2008) e Diehl \& Tatin (2004). Com relação aos estudos empíricos, têm-se, no exterior, os realizados por Stening \& Sku- 
bik (2007) e Miyazaki \& Taylor (2008). Já, no Brasil, têm-se, dentre outros, os realizados por Leite, Tacconi, El-Aouar, Mól \& Alexandre (2009) e Leite; Alexandre; Tacconi; Araujo (2010) que investigaram as questões éticas nas pesquisas em administração. Os resultados por eles obtidos reafirmam a urgência de pesquisas sobre esse tema no campo das ciências sociais aplicadas.

$\mathrm{Na}$ pesquisa contábil brasileira, não se tem conhecimento da existência de um código de ética formal que sirva como orientação de conduta, tanto para o processo de desenvolvimento da pesquisa, como para o processo de orientação de alunos e, ainda, para balizar as relações entre os pares na elaboração de pesquisas conjuntas e na divulgação dos resultados. Adicionalmente, a despeito do Global Code of Ethics for Accounting Educators do The International Association for Accounting Education and Research (IAAER), ainda se tem, no Brasil, a ideia de que códigos de ética formalizados em pesquisa são inerentes aos estudos na área da saúde (PAIVA, 2005), por eles poderem conter procedimentos considerados invasivos e/ou causarem danos de natureza psicológica ou física ao ser humano. É senso comum que os pesquisadores se baseiam em normas tácitas e, geralmente, consultam seus colegas quando se deparam com questões que suscitam um dilema ético e, muito raramente, consultam os Comitês de Ética de suas Universidades.

É nesse contexto e motivado pelos estudos de Leite et al. (2009) e Leite et al. (2010), que se insere a presente pesquisa cujo objetivo principal foi o de conhecer como os acadêmicos do campo das ciências contábeis percebem os aspectos éticos da pesquisa nas seguintes dimensões: processo de pesquisa; orientação de alunos e relação com os seus pares e disseminação do conhecimento.

Como objetivos específicos, têm-se 1) identificar as questões éticas que envolvem a pesquisa científica segundo a crença dos respondentes em nível de importância e 2) identificar a prática (práxis) do pesquisador em relação a essas questões.

A análise conjunta dos resultados obtidos permitirá avaliar eventuais divergências entre a crença e a prática (práxis) fundamentada na visão de Foucault (1984). Essa visão preconiza que o comportamento ético do indivíduo recai muito mais nas formas de subjetivação e nas práticas do ser do que na observância de um código de ética. Nesse contexto, dado um código de ações, há diferentes maneiras de se conduzir moralmente para o indivíduo que procura atuar como sujeito moral de sua ação, transformando-se em um sujeito da ética e, não simplesmente, como agente da ética ou sujeito universal (FOUCAULT, 1984, p.36).

A principal contribuição deste estudo é a de se conhecer e elencar o conjunto de valores que balizam a condução da pesquisa em contabilidade, nas dimensões já mencionadas, por aqueles que a desenvolvem e, também, de se conhecer como esses praticam tais valores numa relação consigo mesmo, contribuindo, assim, para a reflexão sobre a importância dos valores morais do indivíduo que o transformam em um sujeito da ética (FOUCAULT, 1984).

\section{REFERENCIAL TEÓRICO}

\subsection{Códigos de ética para cientistas}

Se por um lado a pesquisa científica pode ser considerada indispensável para o desenvolvimento da humanidade contribuindo para resolver grande parte dos seus proble- mas, por outro, pode, também, direta e indiretamente, agravá-los (GUSTAFSSON, et al. 1984). Assim, é necessário que os pesquisadores identifiquem as questões éticas que podem surgir ao longo do desenvolvimento de 
seus estudos (CRESWELL, 2003). A reflexão ética e a responsabilidade dos cientistas sobre o impacto da ciência e da tecnologia na sociedade não é uma preocupação recente. No século XIX, isso foi muito discutido no campo da medicina. Todavia, foi a partir das consequências desastrosas do uso da ciência aplicada, na Segunda Guerra Mundial, que esse tema passou a ser mais fortemente questionado (SANTOS \& SILVA NETO, 2000).

Mais recentemente, em 1984, em decorrência da preocupação relativa às aplicações e consequências da investigação científica, um pequeno grupo de cientistas publicou a versão final de um código de ética que pode ser aplicado aos vários campos do conhecimento. Esse código, denominado 'The
Uppsala Code of Ethics for Scientists' é destinado ao cientista individual para nortear a avaliação das consequências de suas pesquisas, já que a sua conduta ética depende da sua reflexão pessoal sobre o que considera certo e errado. O Quadro 1 mostra, resumidamente, os quatro aspectos específicos abordados no referido código.

Em 2001, a Divisão de Ética para a Ciência e Tecnologia da UNESCO, juntamente com o Conselho Internacional para a Ciência (ICSU), formularam o 'ICSU Standards for Ethics and Responsibility in Science'(SCHOLZE, 2001). O Quadro 2 mostra os aspectos essenciais ou virtudes relacionados à conduta individual do pesquisador e, também, aqueles relacionados à comunidade científica, segundo o referido código.

\section{Quadro 1 Aspectos abordados no The Uppsala Code of Ethics for Scientists}

\footnotetext{
1. Investigação científica deve ser conduzidad de forma que as suas aplicações, e outras consequências, não causem danos ecológicos significativos.

2. Investigação científica deve ser conduzidad de forma que suas consequências não comprometam as gerações presentes e futuras e as conduzam a uma existência segura. As habilidades científicas não devem ser empregadas visando a guerra ou a opressão.

3. O cientista tem a responsabilidade especial de avaliar cuidadosamente as consequências do seu projeto de pesquisa e o dever de divulgá-lo publicamente.

4. Os cientistas que estão realizando ou participando de pesquisas que estejam em conflito com este código, devem interromper essas pesquisas e tornar público as razões da decisão tomada.
}

Fonte: Gustafsson et al., 1984.

Quadro 2 ICSU Standards for Ethics and Responsibility in Science

\begin{tabular}{|c|c|c|c|}
\hline \multicolumn{4}{|c|}{ Aspectos essenciais relacionados à conduta individual } \\
\hline Honestidade & Franqueza & & Equidade \\
\hline Verdade & Acurácia & & Consiência \\
\hline Respeito & Colaboração & & Lealdade \\
\hline \multicolumn{4}{|c|}{ Aspectos essenciais relacionados à comunidade científica } \\
\hline \multicolumn{2}{|c|}{ Responsabilidade Social } & \multicolumn{2}{|c|}{ Responsabilidade Ambiental } \\
\hline \multicolumn{2}{|c|}{ Desenvolvimento Sustentável } & \multicolumn{2}{|c|}{ Equidade Socioeconômico } \\
\hline \multicolumn{2}{|c|}{ Desenvolvimento Socioeconômico } & \multicolumn{2}{|l|}{ Assitência Social } \\
\hline \multicolumn{2}{|c|}{ Liberdade Científica } & \multicolumn{2}{|l|}{ Igualdade de Gênero } \\
\hline \multicolumn{2}{|l|}{ Paz } & \multicolumn{2}{|c|}{ Desenvolvimento Democrático } \\
\hline \multicolumn{2}{|c|}{ Direitos Humanos } & \\
\hline
\end{tabular}

Fonte: Gustafsson et al., 1984.

Em 2002, a International Association for Accounting Education and Research (IAA-
ER) publicou um código de ética denominado 'Global Code of Ethics for Accounting 
Educators' (NEEDLES Jr., 2008) que foi formulado com o objetivo de promover a excelência na pesquisa em educação e contabili- dade em bases mundial. Os pontos principais desse código, no que se refere ao tema em questão, estão sintetizados no Quadro 3.

Quadro 3 Responsabilidades na pesquisa acadêmica segundo Global Code of Ethics for Accounting Educators

\begin{tabular}{|l|l|l|}
\hline $\begin{array}{l}\text { 1) Responsabilidades na misão de } \\
\text { pesquisador }\end{array}$ & 2) Realização da pesquisa & $\begin{array}{l}\text { 3) Periódicos científicos e políticas } \\
\text { de publicação }\end{array}$ \\
\hline $\begin{array}{l}\text { A missão do pesquisador requer que } \\
\text { as pesquisas desenvolvidas sejam } \\
\text { destinadas a melhorar a qualidade do } \\
\text { ensino e da prática contábil. }\end{array}$ & $\begin{array}{l}\text { Os educadores de contabilidade } \\
\text { devem respeitar a propriedade } \\
\text { intelectual atribuindo os respectivos } \\
\text { créditos de autoria. }\end{array}$ & $\begin{array}{l}\text { Editores e revisores de trabalhos } \\
\text { científicos devem garantir a imparcia- } \\
\text { lidade na avaliação dos trabalhos } \\
\text { submetidos. }\end{array}$ \\
\hline $\begin{array}{l}\text { Ao realizar a pesquisa, os educadores } \\
\text { de contabilidade devem manter um } \\
\text { elevado nível de desempenho profis- } \\
\text { sional e moral. }\end{array}$ & $\begin{array}{l}\text { A pesquisa científica exige hones- } \\
\text { tidade, objetividade e precisão na } \\
\text { divulgação dos resultados. }\end{array}$ & $\begin{array}{l}\text { O revisor de pesquisa científica tem o } \\
\text { dever de revelar conflitos de interesse } \\
\text { para o conselho editor ou comissão } \\
\text { científica. }\end{array}$ \\
\hline $\begin{array}{l}\text { A análise e divulgação dos relatórios } \\
\text { das pesquisas exigem uma atitude } \\
\text { profissional. }\end{array}$ & O plágio deve ser comunicado. & $\begin{array}{l}\text { Editores de revistas (ou comissão } \\
\text { científica) devem especificar os } \\
\text { procedimentos para submissão de } \\
\text { trabalhos. }\end{array}$ \\
\cline { 2 - 3 } & $\begin{array}{l}\text { É adequado manter a confidenciali- } \\
\text { dade das fontes. }\end{array}$ & $\begin{array}{l}\text { Os avaliadores de trabalhos científi- } \\
\text { cos devem ser positivos e respeitosos } \\
\text { ao comunicar os resultados aos } \\
\text { autores. }\end{array}$ \\
\hline
\end{tabular}

Fonte: Global Code of Ethics for Accounting Educators do IAAER (NEEDLES Jr., 2008).

Os exemplos mencionados não são exaustivos, uma vez que existem outros mais específicos elaborados por associações profissionais. Estudos desenvolvidos na área das ciências sociais aplicadas e da contabilidade em particular são apresentados na sequência.

\subsection{Estudos éticos relacionados à pesquisa em Ciências Sociais Aplicadas}

Creswell (2003) considera que os pesquisadores precisam se antecipar às questões éticas que possam surgir durante o processo de execução de sua pesquisa. Os cinco principais pontos abordados pelo autor estão resumidos a seguir:

1. Na contextualização do problema de pesquisa: na introdução do estudo, é importante identificar-se um problema que beneficie os indivíduos estudados, ou seja, um problema que, também, seja significativo para as outras pessoas e não apenas para o pesquisador.
2. No objetivo e nas questões de pesquisa: é importante transmitir-se a finalidade e as questões do estudo aos participantes; deve-se mencionar o patrocínio do estudo de modo a se estabelecer a credibilidade do instrumento de pesquisa que está sendo encaminhado.

3. Na coleta de dados: é importante respeitar os participantes e os locais da coleta de dados, assim como preservar a sua confidencialidade; deve-se avaliar a possibilidade de serem divulgadas informações, obtendo-se, para tanto, a permissão das pessoas participantes.

4. Na análise e interpretação dos dados: é importante proteger o anonimato dos indivíduos e das suas funções; conservar os dados coletados; refletir sobre quem os detém e fornecer um relato preciso das informações geradas.

5. Na redação e na divulgação da pesquisa: não utilizar linguagem preconceituosa; não suprimir, falsificar ou inventar re- 
sultados para se atenderem necessidades específicas; prever a repercussão de se conduzir pesquisa com determinado público e não usar os resultados para a vantagem de outro grupo; reconhecer a contribuição das pessoas que colaboram na pesquisa; não publicar em mais de um periódico a pesquisa realizada.

Com relação aos estudos empíricos relacionados à pesquisa em contabilidade, vale mencionar o estudo realizado por Stening \& Skubik (2007) no qual os autores investigaram os dilemas éticos em pesquisas na área da contabilidade gerencial, particularmente quando realizadas em contextos interculturais. Na visão dos referido autores, esses dilemas éticos, frenquentemente, não são entendidos pelos pesquisadores e, raramente, são discutidos e enfrentados. Concluíram, ainda, que não ficou claro se a existência de um código de ética internacional para os pesquisadores em contabilidade gerencial resolveria a questão, já que existem diferentes visões do que constitui uma conduta ética nos diferentes países. Diante desse contexto, os autores propoem que os pesquisadores internacionais em contabilidade gerencial façam uma reflexão para analisar os aspectos éticos envolvidos em suas pesquisas.

Tem-se, também, a pesquisa de Miyazaki \& Taylor (2008) que teve como foco os vieses nas respostas quando os pesquisadores interagem com os participantes. Nessa pesquisa, os autores concluíram que a presença dos pesquisadores, no ambiente em que a pesquisa está sendo realizada, de certa forma impacta nas respostas ou ações dos respondentes e demostraram, ainda, que as características psicológicas, físicas e a expertise dos pesquisadores têm o potencial de causar vieses nos resultados.

No Brasil, destaca-se o recente estudo realizado por Leite et al.(2010) que buscaram conhecer a percepção dos pesquisadores em administração sobre a ética na pesquisa. Os resultados mostraram que os respondentes relacionam a ética na pesquisa ao compromisso moral do pesquisador e, também, ao respeito às normas éticas. Quanto aos dilemas éticos, os autores observaram que há uma grande preocupação em relação à conduta ética no que tange às questões de plágio e ao anonimato dos respondentes. Dessa forma, concluíram que, embora a maioria dos pesquisadores não conheça os códigos de ética na pesquisa, acreditam ser fundamental a sua discussão, elaboração, divulgação e aplicação.

Considerando que se entende que a existência de um código de ética não é o suficiente para assegurar uma conduta ética adequada, apresentam-se, na seção seguinte, as ideias de Foucault sobre a observância de padrões éticos que fundamentam este estudo.

\subsection{Conduta ética e a relação do indivíduo consigo mesmo segundo Foucault}

Etimologicamente, a palavra "ética" origina-se do termo grego ethos, significando o conjunto de costumes, hábitos e valores de uma determinada sociedade ou cultura. Foi traduzido pelos romanos para o latim como mos, moris, dos quais provém moralis, originando a palavra moral em português, a qual tem o mesmo significado de ethos (MARCONDES, 2009).

Embora Lalande (1985, p. 413) observe que os filósofos alemães seguidores de Kant tendem a separar ética e moral para colocar a primeira acima da outra, citando Schelling e Hegel, Boillot (2007, p.712 e 713), no Petit Larousse de la Philosophie, ressalta que, atualmente, também se entendem por ética as regras morais de conduta de uma profissão. Dessa forma, o termo conduta ética tem o mesmo significado de conduta moral, visto, ainda, que os códigos que regulam a conduta moral dos profissionais são denominados Código de Ética Profissional.

Foucault (1984, p.36), por sua vez, apresenta dois entendimentos para moral: 1) um 
conjunto de valores e regras de ação (normas) para indivíduos e grupos, por meio da prescrição de vários instrumentos que podem ser, explícita e claramente, divulgados ou transmitidos de forma difusa e 2) o comportamento real dos indivíduos em relação a essas regras e valores (normas) que lhes são propostos, designando, dessa forma, a maneira pela qual eles se submetem ou obedecem ou resistem ou respeitam ou negligenciam, mais ou menos completamente, um conjunto de valores. Dessa forma, de acordo com Castro (2009, p.155), no primeiro caso, Foucault refere-se ao código moral e, no segundo, à moralidade dos comportamentos.

Segundo Diáz (2005, p.130), na análise dos textos pagãos e cristãos, Foucault encontrou temas recorrentes que permearam toda a cultura ocidental. Nesse conjunto de textos, destaca-se além da regra de conduta e da conduta que se realiza e é medida por esta regra, a disposição de cada indivíduo em relação a si mesmo, ou seja, a maneira pela qual o indivíduo deve constituir-se como um sujeito moral que atua em referência aos elementos prescritivos que constituem o código.

De acordo com esse entendimento, diante de um código de ações, há diferentes maneiras de o indivíduo se conduzir moralmente procurando atuar como sujeito moral de sua ação, transformando-se em um sujeito da ética e, não, simplesmente, como agente da ética. Essa constituição do sujeito é determinada pela relação dele consigo mesmo na qual ele se define a partir de quatro instâncias: 1) Determinação da substância ética; 2) Modos de sujeição; 3 ) Elaboração do trabalho ético e 4) Teleologia do sujeito moral (DIÁZ, 2005, p.130-133).

A determinação da substância ética (instância 1) está baseada na maneira como o indivíduo, enquanto pertencente a um grupo, dá forma a si mesmo, pois surge de um valor moral que ele aceita como tal; assim, o valor do grupo serve-lhe como matéria-prima para definir a sua conduta moral, respondendo à seguinte pergunta: que parte de mim mesmo, ou de minha conduta, concerne à conduta moral?

O modo de sujeição (instância 2) é a forma com a qual o indivíduo se reconhece ligado à regra estabelecendo sua relação com ela. Esse aspecto está relacionado com a maneira pela qual a pessoa é incitada a reconhecer as suas obrigações morais, respondendo às seguintes questões: devo obedecer à lei divina que foi revelada em um texto? As leis da natureza regem da mesma forma cada ser vivente?

A elaboração do trabalho ético (instância 3) é caracterizada pela transformação que o indivíduo realiza em si mesmo; trata-se de uma ascesis (ascetismo em sentido amplo) por meio da qual o homem se transforma em sujeito moral de suas condutas. Objetivamente, trata-se de moderar os atos, de decifrar os desejos, de controlar-se para realizar, ou não, determinadas ações, segundo considerações positivas ou negativas. Nesse caso, podem-se propor etapas para se atingir uma conduta desejável ou, ao contrário, pode-se decidir, bruscamente, a cortar hábitos não valorizados e adquirir outros.

A quarta e última instância (Teleologia do sujeito moral) está relacionada com a inserção de cada ação no conjunto das condutas. Uma ação moral tende a seu próprio cumprimento, mas, além disso, objetiva a constituição de uma conduta moral que leve o indivíduo não somente a ações sempre conformes a certos valores, mas, também, a certo modo de ser que caracteriza cada sujeito moral. Algumas perguntas próprias da Teleologia da ética, em cujo sentido se inserem as condutas que o sujeito vai realizando, podem ser: Persigo o autodomínio? Quero ser uma alma bela? Aspiro a ser um bom cidadão?

Em resumo, para Foucault, uma ação moral inscreve-se em: a) um código ao qual a ação moral se refere e que não depende do sujeito; b) uma conduta que depende da relação do sujeito com o código e c) uma determinada relação do sujeito consigo 
mesmo na qual ele se define a partir de: 1) a substância ética; 2) os modos de sujeição; 3) o trabalho sobre si e 4) a Teleologia (dependente da relação com o seu código individual).

Dessa forma, conforme Castro (2009, p.156), Foucault distingue morais orientadas para o código (em que o elemento prescritivo é ressaltado) e morais orientadas para ética (em que a insistência recai nos modos de subjetivação), ou seja, o termo ética está referenciado à relação consigo mesmo, tratando-se de uma prática, de um modo de ser, referindo-se a todo esse domínio da constituição de si mesmo como sujeito moral. Logo, ainda segundo Castro (2009, p.156), "as expressões sujeito moral e sujeito ético são equivalentes no uso que Foucault faz deles". Por fim, vale mencionar que, de acordo com de Foucault, a transformação do homem, para atuar como sujeito moral de sua ação, dá-se, gradualmente, por meio do exercício da prática e da construção do seu discurso (DIÁZ, 2005, p.133).

\section{PROCEDIMENTOS METODOLÓGICOS}

Este estudo enquadra-se nos tipos exploratório e descritivo em relação aos seus objetivos (BEUREN, 2008); quanto aos procedimentos para a coleta de dados trata-se de um levantamento (survey) com abordagem quantitativa (COLLIS \& HUSSEY, 2005). A população do estudo é composta pelos 218 professores que integram os 18 Programas de Pós-Graduação em Ciências Contábeis atualmente existentes no Brasil, conforme informações obtidas nos sítios dos respectivos programas e no da Associação Nacional dos Programas de Pós Graduação em Ciências Contábeis (ANPCONT).

Os dados foram coletados por meio de um questionário estruturado e dividido em três partes, seguindo-se as orientações de Hill \& Hill (2008). Na primeira parte, buscou-se caracterizar o respondente em termos de atuação como orientador e pesquisador, tempo de atuação e consultas ao Comitê de Ética de sua Instituição.

Na segunda parte, objetivou-se identificar as questões éticas que envolvem a pesquisa científica segundo a crença dos respondentes em nível de importância, em três dimensões (Objetivo específico 1), a saber: A) aspectos éticos relacionados ao processo de pesquisa; B) aspectos éticos relacionados à orientação de alunos e $\mathrm{C}$ ) aspectos éticos relacionados à relação com os pares e à disseminação dos resultados. Para tanto, formularam-se 19 assertivas (assertivas 14 a 32,) fundamentadas em Gustafsson et al.,1984; Creswell, 2003; Needles Jr., 2008; Miyazaki \& Taylor (2008) e Leite et al., 2010. A escala Likert adotada foi de 5 pontos variando de 1 - nenhuma importância a 5 extrema importância.

Na terceira e última parte, buscou-se identificar a prática (práxis) do pesquisador em relação às três dimensões mencionadas $(\mathrm{Ob}-$ jetivo específico 2). Para tanto, utilizaram-se 19 assertivas (assertivas 33 a 51), relacionadas com as utilizadas na parte 2 , o que permitiu identificar diferenças entre a crença e a prática. A escala Likert de 5 pontos foi construída atribuindo-se o valor 1 - nunca pratico a 5 sempre pratico.

Após pré-teste, o link do questionário foi disponibilizado em uma página da Web de 01 e 31/11/10 e encaminhado aos coordenadores dos 18 programas com uma solicitação para que fosse respondido pelos professores de seus programas. Dessa população de 218 professores, obteve-se o retorno de 56 questionários ( $26 \%$ da população). Todas as respostas foram aproveitadas para a análise que segue, a qual foi realizada por meio de estatística descritiva e de testes não paramétricos, utilizando-se o SPSS Statistics 17.0. 


\section{APRESENTAÇÃO E ANÁLISE DOS RESULTADOS}

\section{Caracterização da Amostra}

A amostra final foi composta por 56 acadêmicos com titulação de doutor, incluindose dentre esses aqueles com pós-doutorado $(10 \%)$ e em sua maioria homens $(80,36 \%)$.
Considerando a idade, a experiência em pesquisa e a experiência em orientação de pesquisas dos respondentes, os resultados são apresentados na Tabela 1:

Tabela 1

Caracterização da amostra

\begin{tabular}{c|c|c|c|c|c|c|c|c}
\hline Faixa de Idade & Qtd. & $\mathbf{\%}$ & $\begin{array}{c}\text { Experiência como } \\
\text { Pesquisador }\end{array}$ & Qtd. & $\mathbf{\%}$ & $\begin{array}{c}\text { Experiência como } \\
\text { Orientador }\end{array}$ & Qtd. & \% \\
\hline Total & 56 & $100 \%$ & Total & 56 & $100 \%$ & Total & 56 & $100 \%$ \\
\hline $30-40$ anos & 11 & $19,64 \%$ & $0-5$ anos & 7 & $12,5 \%$ & $0-5$ anos & 28 & $50 \%$ \\
\hline $41-50$ anos & 20 & $35,71 \%$ & $6-10$ anos & 23 & $41,07 \%$ & $6-10$ anos & 19 & $33,93 \%$ \\
\hline $51-60$ anos & 15 & $26,79 \%$ & $11-15$ anos & 10 & $17,86 \%$ & $11-15$ anos & 7 & $12,5 \%$ \\
\hline Acima de 61 anos & 10 & $17,86 \%$ & $16-20$ anos & 8 & $14,29 \%$ & $16-20$ anos & 1 & $1,79 \%$ \\
\hline & & & Acima de 21 anos & 8 & $14,29 \%$ & Acima de 21 anos & 1 & $1,79 \%$ \\
\hline
\end{tabular}

O exame dos dados contidos na Tabela 1 permite verificar que, em relação à experiência como pesquisador, a maioria $(41,07 \%)$ atua de 6-10 anos; $17,86 \%$ de 11-15 anos; $14,29 \%$ de 16-21 anos; 14,29\% há mais de 21 anos e 12,50\% há menos de 5 anos. Todos conduzem orientação de pesquisas (dissertações e/ou teses) e 54 deles, também, orientam trabalhos de conclusão de curso de graduação. Em relação ao tempo de atuação como orientadores, $50 \%$ dos respondentes possuem menos de 5 anos de experiência.

Cabe ressaltar que a amostra do estudo representa a realidade do corpo docente dos cursos de pós-graduação em ciências contábeis no Brasil, que se iniciou com o curso de mestrado em 1970 e de doutorado em 1978 na Universidade de São Paulo. Nesse mesmo ano, o curso de mestrado na Pontifícia Universidade Católica - SP foi criado. Após esse período, de 1998 a 2008, 15 novos programas foram formados (PELEIAS et al., 2010).

Por fim, os respondentes foram questionados sobre os Comitês de Ética das suas Universidades. Em relação a isso, verificou-se que mais da metade dos respondentes $(64,29 \%)$ afirmaram conhecer os seus objetivos, mas apenas 7 deles (12,5\%) afirmaram já o terem consultado. Esses resultados sugerem que as diretrizes dos comitês de ética podem não ser consideradas pelos pesquisadores dessa amostra como aplicáveis à área de ciências sociais, como relatado previamente.

\section{Análise das Estatísticas Descritivas}

A Tabela 2 exibe as assertivas e suas respectivas estatísticas descritivas em termos de frequência, média, moda e desvio-padrão. Em relação ao objetivo específico 1, esses resultados evidenciam que a maior parte das assertivas das dimensões A, B e C (assertivas 14 a 32) possuem uma moda de 5 (Extrema importância), exceto pela assertiva 25 (moda $=3)$ e assertiva $26($ moda $=4)($ Tabela 2$)$.

Dessa forma, conforme evidencia a Tabela 2, pode-se observar que todos os aspectos elencados, nas três dimensões, são importantes segundo a crença dos respondentes, considerando o valor 5 como moda; exceto nas assertivas 25 (Deixar que o aluno escolha por iniciativa própria o seu tema de pesquisa, moda $=3$ ) e 26 (Estabelecimento de uma programação/agenda de orientação, $\operatorname{moda}=4)$. 
Tabela 2 Parte 2: Identificação dos aspectos éticos relacionados à atividade de pesquisa

\begin{tabular}{|c|c|c|c|c|c|c|c|c|c|}
\hline & & & Frequêr & cia de & esposta & & & & \\
\hline Dimensões & Assertivas / Identificação & 1 & 2 & 3 & 4 & 5 & Moda & Média & Desvio \\
\hline \multirow{10}{*}{$\begin{array}{l}\text { A) Aspectos éticos } \\
\text { relacionados ao pro- } \\
\text { cesso de pesquisa }\end{array}$} & $\begin{array}{l}\text { 14. No planejamento da pesquisa refletir se o estudo pode trazer } \\
\text { benefícios ou não trazer prejuízos para a sociedade como um todo }\end{array}$ & $1,79 \%$ & $0 \%$ & $12,5 \%$ & $32,14 \%$ & $53,57 \%$ & 5 & 4,36 & 0,84 \\
\hline & 15. Apresentar-se e comunicar o objetivo do estudo aos participantes & $0 \%$ & $0 \%$ & $8,93 \%$ & $28,57 \%$ & $62,5 \%$ & 5 & 4,54 & 0,66 \\
\hline & $\begin{array}{l}\text { 16. Informar quem patrocina a pesquisa (Instituição de fomento; } \\
\text { empresa; associação de classe etc.) }\end{array}$ & $3,57 \%$ & $1,79 \%$ & $12,5 \%$ & $37,5 \%$ & $44,64 \%$ & 5 & 4,18 & 0,97 \\
\hline & $\begin{array}{l}\text { 17. Obter por escrito, de pessoa habilitada, a autorização para } \\
\text { divulgar o(s) nome(s) da(s) empresa(s) pesquisada(s), quando se tratar } \\
\text { de dados primários }\end{array}$ & $1,79 \%$ & $0 \%$ & $10,71 \%$ & $16,07 \%$ & $71,43 \%$ & 5 & 4,55 & 0,83 \\
\hline & $\begin{array}{l}\text { 18. Divulgar no relatório final de pesquisa a autorização para divulgar } \\
\text { o(s) nome(s) da(s) empresa(s) pesquisada(s), quando se tratar de dados } \\
\text { primários }\end{array}$ & $3,57 \%$ & $7,14 \%$ & $12,5 \%$ & $30,36 \%$ & $46,43 \%$ & 5 & 4,09 & 1,10 \\
\hline & $\begin{array}{l}\text { 19. Na elaboração do instrumento de coleta de dados evitar pergun- } \\
\text { tas potencialmente constrangedoras }\end{array}$ & $1,79 \%$ & $0 \%$ & $10,71 \%$ & $37,5 \%$ & $50 \%$ & 5 & 4,34 & 0,82 \\
\hline & $\begin{array}{l}\text { 20. Disponibilizar os resultados da pesquisa sempre que solicitado } \\
\text { pelos participantes }\end{array}$ & $0 \%$ & $0 \%$ & $1,79 \%$ & $28,57 \%$ & $69,64 \%$ & 5 & 4,68 & 0,51 \\
\hline & 21. Manter o anonimato das pessoas/empresas pesquisadas & $0 \%$ & $0 \%$ & $8,93 \%$ & $25 \%$ & $66,07 \%$ & 5 & 4,57 & 0,66 \\
\hline & 22. Manter-se fiel aos dados/informações coletados & $0 \%$ & $0 \%$ & $0 \%$ & $5,36 \%$ & $94,64 \%$ & 5 & 4,95 & 0,23 \\
\hline & $\begin{array}{l}\text { 23. Manter a fidedignidade dos resultados obtidos independentemen- } \\
\text { te de contrariarem a hipótese levantada }\end{array}$ & $0 \%$ & $0 \%$ & $0 \%$ & $5,36 \%$ & $94,64 \%$ & 5 & 4,95 & 0,23 \\
\hline \multirow{5}{*}{$\begin{array}{l}\text { B) Aspectos éticos } \\
\text { relacionados à orien- } \\
\text { tação de alunos }\end{array}$} & $\begin{array}{l}\text { 24. Estabelecimento de um processo transparente de atribuição de } \\
\text { orientandos aos seus respectivos orientadores }\end{array}$ & $1,79 \%$ & $0 \%$ & $8,93 \%$ & $26,79 \%$ & $62,5 \%$ & 5 & 4,48 & 0,81 \\
\hline & $\begin{array}{l}\text { 25. Deixar que o aluno escolha por iniciativa própria o seu tema de } \\
\text { pesquisa }\end{array}$ & $7,14 \%$ & $10,71 \%$ & $30,36 \%$ & $28,57 \%$ & $23,21 \%$ & 3 & 3,50 & 1,18 \\
\hline & 26. Estabelecimento de uma programação/agenda de orientação & $0 \%$ & $3,57 \%$ & $16,07 \%$ & $46,43 \%$ & $33,93 \%$ & 4 & 4,11 & 0,80 \\
\hline & $\begin{array}{l}\text { 27. Solicitar autorização do orientando para a utilização do banco de } \\
\text { dados, por ele levantado, para realização de novas pesquisas }\end{array}$ & $1,79 \%$ & $0 \%$ & $7,14 \%$ & $32,14 \%$ & $58,93 \%$ & 5 & 4,46 & 0,79 \\
\hline & $\begin{array}{l}\text { 28. Estabelecer com o orientando os critérios que definem a ordem } \\
\text { de autoria e co-autoria dos artigos gerados pela pesquisa realizada } \\
\text { pelo aluno }\end{array}$ & $1,79 \%$ & $5,36 \%$ & $5,36 \%$ & $42,86 \%$ & $44,64 \%$ & 5 & 4,23 & 0,91 \\
\hline \multirow{4}{*}{$\begin{array}{l}\text { C) Aspectos éticos } \\
\text { relacionados à rela- } \\
\text { ção com os pares e } \\
\text { à disseminação dos } \\
\text { resultados }\end{array}$} & $\begin{array}{l}\text { 29. Manter-se fiel às ideias dos autores consultados não invertendo } \\
\text { frases ou substituindo palavras por seus sinônimos }\end{array}$ & $0 \%$ & $0 \%$ & $5,36 \%$ & $23,21 \%$ & $71,43 \%$ & 5 & 4,66 & 0,58 \\
\hline & $\begin{array}{l}\text { 30. Estabelecer a priori com os pares os critérios que definem a orde } \\
\text { de autoria e co-autoria de uma pesquisa a ser realizada ou artigo a } \\
\text { ser publicado }\end{array}$ & $1,79 \%$ & $0 \%$ & $14,29 \%$ & $28,57 \%$ & $55,36 \%$ & 5 & 4,36 & 0,86 \\
\hline & $\begin{array}{l}\text { 31. Solicitação de autorização para dar continuidade à pesquisa } \\
\text { iniciada po outro pesquisador do mesmo programa ou IES }\end{array}$ & $1,79 \%$ & $1,79 \%$ & $7,14 \%$ & $33,93 \%$ & $55,36 \%$ & 5 & 4,39 & 0,85 \\
\hline & $\begin{array}{l}\text { 32. Mencionar no relatório de pesquisa a autoria quando se tratar de } \\
\text { continuidade de pesquisa já realizada pelos pares }\end{array}$ & $0 \%$ & $1,79 \%$ & $5,36 \%$ & $33,93 \%$ & $58,93 \%$ & 5 & 4,50 & 0,69 \\
\hline
\end{tabular}

Adicionalmente, considerando moda e frequência, pode-se destacar da Tabela 2 as assertivas unânimes, em cada um das três dimensões, como seguem:

Dimensão A: Aspectos éticos relacionados ao processo de pesquisa científica: Assertiva 22 (moda 5, frequência de 94,6\%): Manter-se fiel aos dados/informações coletados. Assertiva 23 (moda 5, frequência de 94,6\%): Man- ter a fidedignidade dos resultados obtidos independentemente de contrariarem a hipótese levantada. Assertiva 17 (moda 5 com frequência de 71,4\%): Obter por escrito, de pessoa habilitada, a autorização para divulgar $\mathrm{o}(\mathrm{s})$ nome(s) da(s) empresa(s) pesquisada(s), quando se tratar de dados primários.

Dimensão B: Aspectos éticos relacionados à orientação de alunos e na relação entre 
orientador e pesquisador: Assertiva 24 (moda 5 com frequência de 62,5\%): Estabelecimento de um processo transparente de atribuição de orientandos aos seus respectivos orientadores. Assertiva 27 (moda 5 com frequência de 58,9\%): Solicitar autorização do orientando para a utilização do banco de dados, por ele levantado, para a realização de novas pesquisas.

Dimensão C: Aspectos éticos relacionados à relação com os pares e o desenvolvimento de pesquisas conjuntas e a disseminação de resultados: Assertiva 29 (moda 5 com frequência de 71,4\%): Manter-se fiel às ideias de autores consultados não invertendo frases ou substituindo palavras por seus sinônimos.
Assertiva 32 (moda 5 com frequência de 58,9\%): Mencionar no relatório de pesquisa a autoria quando se tratar de continuidade de pesquisa já realizada pelos pares.

Em relação ao objetivo específico 2 , a Tabela 3 exibe as assertivas e suas respectivas estatísticas descritivas em termos de frequência, média, moda e desvio-padrão.

De acordo com o dados contidos na Tabela 3, pode-se verificar que todas as assertivas da parte 3 do questionário (assertivas 33 a 51), também, apresentam uma moda de 5 (Sempre pratico), exceto pela assertiva 45 (Cumpro a programação/agenda de orientação estabelecida com o aluno), cuja moda é igual a 4.

Tabela 3 Parte 3: Identificação da conduta ética adotada na pesquisa

\begin{tabular}{|c|c|c|c|c|c|c|c|c|c|}
\hline & & & Frequêr & lcia de & respost & & & & \\
\hline Dimensões & Assertivas / Identificação & 1 & 2 & 3 & 4 & 5 & Moda & Média & Desvio \\
\hline \multirow{10}{*}{$\begin{array}{l}\text { A) Aspectos éticos } \\
\text { relacionados ao pro- } \\
\text { cesso de pesquisa }\end{array}$} & $\begin{array}{l}\text { 33. Eu reflito sobre as consequências dos resultados da minha pesquisa, } \\
\text { ou seja, se o estudo pode trazer benefícios ou não trazer prejuízos para } \\
\text { a sociedade como um todo }\end{array}$ & $1,79 \%$ & $0 \%$ & $12,5 \%$ & $41,07 \%$ & $44,64 \%$ & 5 & 4,27 & 0,82 \\
\hline & $\begin{array}{l}\text { 34. Eu me apresento como pesquisador e comunico o objetivo do } \\
\text { estudo aos participantes }\end{array}$ & $0 \%$ & $0 \%$ & $7,14 \%$ & $39,29 \%$ & $53,57 \%$ & 5 & 4,46 & 0,63 \\
\hline & 35. Eu informo quem foi o patrocinador da minha pesquisa & $3,57 \%$ & $3,57 \%$ & $7,14 \%$ & $37,5 \%$ & $48,21 \%$ & 5 & 4,23 & 0,99 \\
\hline & $\begin{array}{l}\text { 36. Eu obtenho por escrito, de pessoa habilitada, a autorização para } \\
\text { divulgar o(s) nome(s) da(s) empresa(s) pesquisada(s), quando se tratar } \\
\text { de dados primários }\end{array}$ & $0 \%$ & $1,79 \%$ & $16,07 \%$ & $21,43 \%$ & $60,71 \%$ & 5 & 4,41 & 0,83 \\
\hline & $\begin{array}{l}\text { 37. Eu incluo no relatório final de pesquisa a autorização para divulgar } \\
\text { o(s) nome(s) da(s) empresa(s) pesquisada(s), quando se tratar de dados } \\
\text { primários }\end{array}$ & $8,93 \%$ & $3,57 \%$ & $12,5 \%$ & $28,57 \%$ & $46,43 \%$ & 5 & 4,00 & 1,25 \\
\hline & $\begin{array}{l}\text { 38. Eu evito na elaboração do instrumento de coleta de dados utilizar } \\
\text { perguntas potencialmente constrangedoras }\end{array}$ & $3,57 \%$ & $1,79 \%$ & $7,14 \%$ & $32,14 \%$ & $55,36 \%$ & 5 & 4,34 & 0,96 \\
\hline & 39. Eu disponibilizo os resultados da pesquisa sempre que me solicitado & $1,79 \%$ & $0 \%$ & $1,79 \%$ & $23,21 \%$ & $73,21 \%$ & 5 & 4,66 & 0,69 \\
\hline & $\begin{array}{l}\text { 40. Eu informo no relatório da pesquisa que a identidade dos represen- } \\
\text { tantes e/ou empresas é mantida em sigilo }\end{array}$ & $1,79 \%$ & $0 \%$ & $1,79 \%$ & $26,79 \%$ & $69,64 \%$ & 5 & 4,63 & 0,70 \\
\hline & $\begin{array}{l}\text { 41. Eu não interfiro nos dados/informações coletados à minha } \\
\text { conveniência }\end{array}$ & $1,79 \%$ & $0 \%$ & $3,57 \%$ & $8,93 \%$ & $85,71 \%$ & 5 & 4,77 & 0,69 \\
\hline & 42. Eu me mantenho imparcial diante dos resultados obtidos & $0 \%$ & $0 \%$ & $1,79 \%$ & $26,79 \%$ & $71,43 \%$ & 5 & 4,70 & 0,50 \\
\hline \multirow{5}{*}{$\begin{array}{l}\text { B) Aspectos éticos } \\
\text { relacionados à orien- } \\
\text { tação de alunos }\end{array}$} & $\begin{array}{l}\text { 43. No processo de atribuição de orientandos aos orientadores eu } \\
\text { não interfiro cooptando aqueles que eu identifico como os de maior } \\
\text { potencial técnico e científico }\end{array}$ & $0 \%$ & $8,93 \%$ & $17,86 \%$ & $23,21 \%$ & $50 \%$ & 5 & 4,14 & 1,02 \\
\hline & $\begin{array}{l}\text { 44. Não direciono a pesquisa dos alunos a mim atribuídos para orienta- } \\
\text { ção aos meus interesses pesssoais de pesquisa }\end{array}$ & $3,57 \%$ & $19,64 \%$ & $21,43 \%$ & $26,79 \%$ & $28,57 \%$ & 5 & 3,57 & 1,20 \\
\hline & $\begin{array}{l}\text { 45. Cumpro a programação/agenda de orientação estabelecida com } \\
\text { o aluno }\end{array}$ & $1,79 \%$ & $1,79 \%$ & $17,86 \%$ & $48,21 \%$ & $30,36 \%$ & 5 & 4,04 & 0,85 \\
\hline & $\begin{array}{l}\text { 48. Eu deixo claro para meus orientandos os critérios que definem a } \\
\text { autoria e co-autoria dos artigos gerados pela pesquisa realizada }\end{array}$ & $0 \%$ & $0 \%$ & $5,36 \%$ & $10,71 \%$ & $83,93 \%$ & 5 & 4,79 & 0,53 \\
\hline & $\begin{array}{l}\text { 47. Eu solicito autorização dos meus orientandos quando pretendo } \\
\text { utilizar o banco de dados por ele coletado para novas pesquisas }\end{array}$ & $3,57 \%$ & $0 \%$ & $10,71 \%$ & $33,93 \%$ & $51,79 \%$ & 5 & 4,30 & 0,93 \\
\hline
\end{tabular}


continuação

\begin{tabular}{|c|c|c|c|c|c|c|c|c|c|}
\hline \multirow[b]{2}{*}{ Dimensões } & \multirow[b]{2}{*}{ Assertivas / Identificação } & \multicolumn{5}{|c|}{ Frequência de respostas } & \multirow[b]{2}{*}{ Moda } & \multirow[b]{2}{*}{ Média } & \multirow[b]{2}{*}{ Desvio } \\
\hline & & 1 & 2 & 3 & 4 & 5 & & & \\
\hline \multirow{4}{*}{$\begin{array}{l}\text { C) Aspectos éticos } \\
\text { relacionados à rela- } \\
\text { ção com os pares e } \\
\text { à disseminação dos } \\
\text { resultados }\end{array}$} & 46. Informo a fonte consultada seja por citação literal ou paráfrase. & $0 \%$ & $1,79 \%$ & $8,93 \%$ & $28,57 \%$ & $60,71 \%$ & 5 & 4,48 & 0,74 \\
\hline & $\begin{array}{l}\text { 49. Eu deixo claro com os meus pares os critérios utilizados para identi- } \\
\text { ficar a autoria e co-autoria da pesquisa ou artigo a ser publicado. }\end{array}$ & $0 \%$ & $1,79 \%$ & $10,71 \%$ & $25 \%$ & $62,5 \%$ & 5 & 4,48 & 0,76 \\
\hline & $\begin{array}{l}\text { 50. Eu solicito a autorização do pesquisador para dar continuidade a } \\
\text { sua pesquisa quando pertencemos ao mesmo programa ou trabalhamos } \\
\text { na mesma IES. }\end{array}$ & $3,57 \%$ & $1,79 \%$ & $7,14 \%$ & $28,57 \%$ & $58,93 \%$ & 5 & 4,38 & 0,96 \\
\hline & $\begin{array}{l}\text { 51. Eu menciono no relatório de pesquisa a autoria quando dou conti- } \\
\text { nuidade a pesquisa já realizada pelos pares. }\end{array}$ & $1,79 \%$ & $0 \%$ & $12,5 \%$ & $25 \%$ & $60,71 \%$ & 5 & 4,43 & 0,85 \\
\hline
\end{tabular}

Ainda em relação ao objetivo específico 2 (identificar a prática do pesquisador em relação às questões que valoriza no processo de pesquisa), apresenta-se a Figura 1. Essa figura exibe a Moda que é a resposta de maior frequência das respostas para as questões Q14 a Q32 (crença), em escala ordinal 1: Nenhuma Importância a 5: Extrema Importância, pareadas com as respostas para as questões Q33 a Q51 (práxis), também em escala ordinal 1: Nunca pratico a 5: Sempre pratico.
Pode-se visualizar que há uma diferença nas assertivas Q25 \& Q44. Isso significa que enquanto a maioria dos respondentes considera de extrema importância (moda 5) "Deixar que o aluno escolha por iniciativa própria o seu tema de pesquisa", também considerou de importância média (moda 3) a assertiva "Não direciono a pesquisa dos alunos a mim atribuídos para orientação aos meus interesses pessoais de pesquisa”.

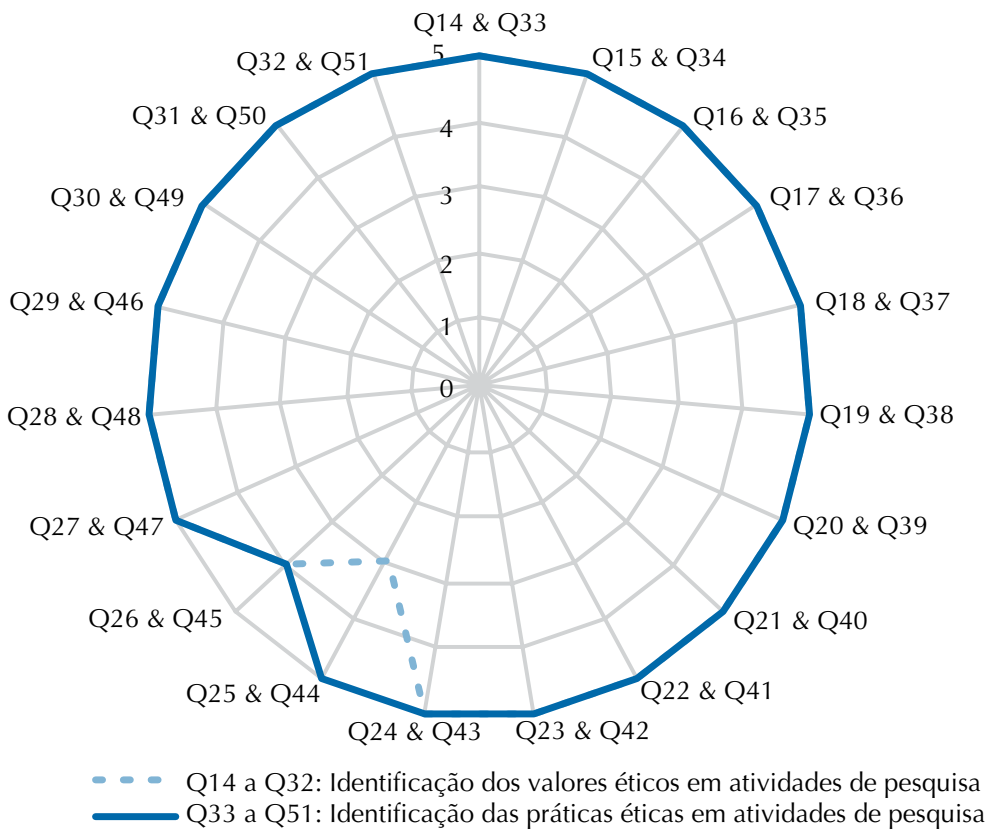

Figura 1 Moda das respostas para as questões 14 a 32 (em escala ordinal 1: Nenhuma Importância a 5: Extrema Importância) pareadas com as respostas para as questões 33 a 51 (em escala ordinal 1: Nunca pratico a 5: Sempre pratico) 
A Figura 2 exibe a frequência da moda para as questões Q14 a Q32 pareadas com a frequência da moda para as questões Q33 a Q51. Pode-se visualizar que apesar das res- postas predominantes serem iguais à escala máxima, moda 5 (5: Extrema Importância e 5: Sempre Pratico), há uma diferença de frequência da moda dependendo da questão.

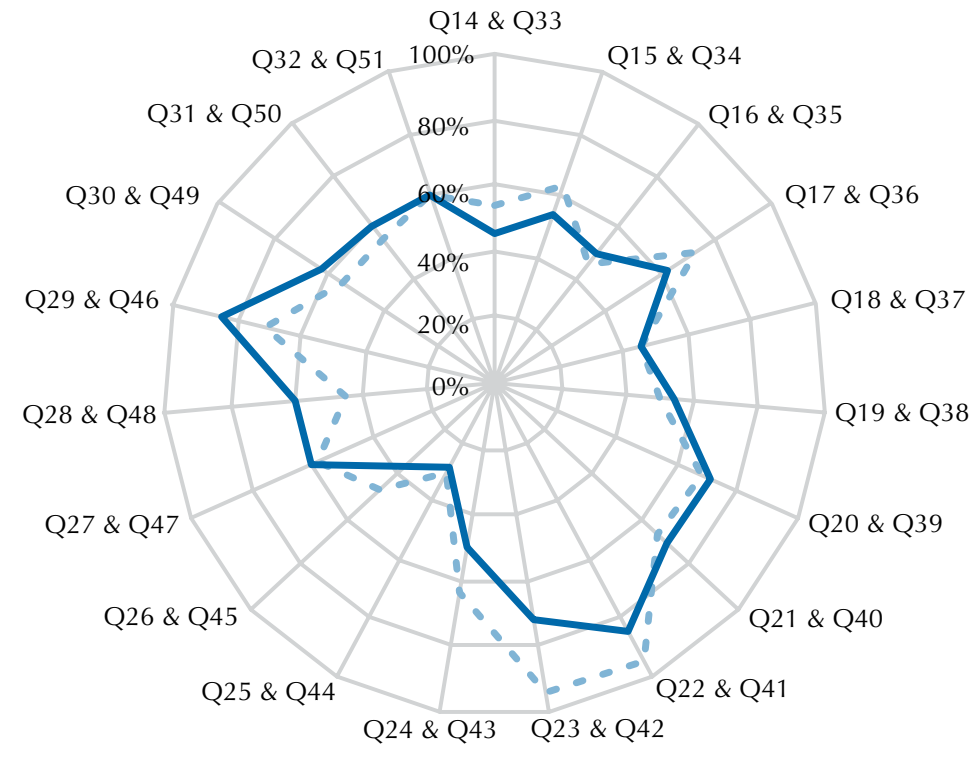

- Q14 a Q32: Identificação dos valores éticos em atividades de pesquisa Q33 a Q51: Identificação das práticas éticas em atividades de pesquisa

Figura 2 Frequência (da moda) para as questões 14 a 32 pareadas com a frequência (da moda) para as questões 33 a 51

Em resumo, a Tabela 4 exibe as estatísticas pareadas que deram origem às figuras 1 e 2 . (moda e frequência da moda) das questões

Tabela 4 Estatísticas descritivas das assertivas pareadas: crenças versus práxis

\begin{tabular}{l|c|c|c|c|c|c|c|c|c|c}
\hline Assertivas da Parte 2 & Q14 & Q15 & Q16 & Q17 & Q18 & Q19 & Q20 & Q21 & Q22 & Q23 \\
\hline Moda & 5 & 5 & 5 & 5 & 5 & 5 & 5 & 5 & 5 & 5 \\
\hline Frequência da Moda & $53,6 \%$ & $62,5 \%$ & $44,6 \%$ & $71,4 \%$ & $46,4 \%$ & $50 \%$ & $69,6 \%$ & $66,1 \%$ & $94,6 \%$ & $94,6 \%$ \\
\hline Assertivas da Parte 2 & $\mathbf{Q 2 4}$ & $\mathbf{Q 2 5}$ & $\mathbf{Q 2 6}$ & $\mathbf{Q 2 7}$ & $\mathbf{Q 2 8}$ & $\mathbf{Q 2 9}$ & $\mathbf{Q 3 0}$ & $\mathbf{Q 3 1}$ & $\mathbf{Q 3 2}$ & \\
\hline Moda & 5 & 3 & 4 & 5 & 5 & 5 & 5 & 5 & 5 & \\
\hline Frequência da Moda & $62,5 \%$ & $30,4 \%$ & $46,4 \%$ & $58,9 \%$ & $44,6 \%$ & $71,4 \%$ & $55,4 \%$ & $55,4 \%$ & $58,9 \%$ & \\
\hline Assertivas da Parte 3 & $\mathbf{Q 3 3}$ & $\mathbf{Q 3 4}$ & $\mathbf{Q 3 5}$ & $\mathbf{Q 3 6}$ & $\mathbf{Q 3 7}$ & $\mathbf{Q 3 8}$ & $\mathbf{Q 3 9}$ & $\mathbf{Q 4 0}$ & $\mathbf{Q 4 1}$ & Q42 \\
\hline Moda & 5 & 5 & 5 & 5 & 5 & 5 & 5 & 5 & 5 & 5 \\
\hline Frequência da Moda & $44,6 \%$ & $53,6 \%$ & $48,2 \%$ & $60,7 \%$ & $46,4 \%$ & $55,4 \%$ & $73,2 \%$ & $69,6 \%$ & $85,7 \%$ & $71,4 \%$ \\
\hline Assertivas da Parte 3 & $\mathbf{Q 4 3}$ & $\mathbf{Q 4 4}$ & $\mathbf{Q 4 5}$ & $\mathbf{Q 4 7}$ & $\mathbf{Q 4 8}$ & $\mathbf{Q 4 6}$ & $\mathbf{Q 4 9}$ & $\mathbf{Q 5 0}$ & $\mathbf{Q 5 1}$ & \\
\hline Moda & 5 & 5 & 4 & 5 & 5 & 5 & 5 & 5 & 5 & \\
\hline Frequência da Moda & $50 \%$ & $28,6 \%$ & $48,2 \%$ & $51,8 \%$ & $60,7 \%$ & $83,9 \%$ & $62,5 \%$ & $58,9 \%$ & $60,7 \%$ & \\
\hline
\end{tabular}




\section{Análise dos Testes Estatísticos}

Para se testarem, estatisticamente, as diferenças de respostas entre a importância e a prática do aspecto ético, foram conduzidos testes não paramétricos como o Teste do Sinal, o Teste de Postos Sinalizados de Wilcoxon e o Teste de Homogeneidade Marginal aplicáveis a variáveis categóricas ordinais (escala Likert). As Tabelas 5 e 6 exibem os resultados dos testes realizados.

O Teste do Sinal considera o sinal (positivo ou negativo) de respostas diferentes de um mesmo respondente, enquanto o Teste de Postos Sinalizados de Wilcoxon, também, leva em conta a magnitude da diferença e, por esse motivo, é considerado mais poderoso que o Teste do Sinal; a sua desvantagem é que toma em consideração uma distribuição simétrica para as diferenças. O Teste de Homogeneidade Marginal é mais apropriado para esse problema, pois generaliza o Teste de McNemar de variáveis binárias para respostas multinomiais e, assim, é testada a diferença entre duas variáveis com respostas categóricas ordinais (GREEN, SALKING \& AKEY, 2000, p. 375-377). Também, foi aplicado o uso de Exact Tests para o cálculo do valor-p, uma vez que é mais confiável quando o tamanho das amostras não é grande o suficiente e os valores-p assintóticos não são precisos (MEHTA \& PATE, 2008, p. 1-2). Os testes não paramétricos e Exact Tests foram estimados com o uso de SPSS Statistics 17.0.

Assim sendo, na Tabela 5, pode-se observar que as respostas para as assertivas 22 e 41 possuem diferença estatisticamente significante em um nível de $10 \%$ com o teste de Wilcoxon e de Homogeneidade Marginal (Exact Sig. 2-tailed $=0.078$ para ambos os testes). As respostas das assertivas 23 e 42, igualmente, possuem diferença estatisticamente significante em um nível de 1\% com todos os testes (Exact Sig. 2-tailed $=0.000$ para todos os testes).

Tabela 5 Testes não paramétricos - Processo de Pesquisas

\begin{tabular}{|c|c|c|c|c|c|c|c|c|c|c|}
\hline \multirow[b]{2}{*}{ Assertivas Pareadas } & \multicolumn{10}{|c|}{ A. Aspectos éticos relacionados ao processo de pesquisa científica } \\
\hline & $\begin{array}{c}\text { Q14 \& } \\
\text { Q33 }\end{array}$ & $\begin{array}{c}\text { Q15 \& } \\
\text { Q34 }\end{array}$ & $\begin{array}{c}\text { Q16 \& } \\
\text { Q35 }\end{array}$ & $\begin{array}{c}\text { Q17 \& } \\
\text { Q36 }\end{array}$ & $\begin{array}{c}\text { Q18 \& } \\
\text { Q37 }\end{array}$ & $\begin{array}{c}\text { Q19 } \\
\text { \& Q38 }\end{array}$ & $\begin{array}{c}\text { Q20 \& } \\
\text { Q39 }\end{array}$ & $\begin{array}{c}\text { Q21 \& } \\
\text { Q40 }\end{array}$ & $\begin{array}{c}\text { Q22 \& } \\
\text { Q41 }\end{array}$ & $\begin{array}{c}\text { Q23 \& } \\
\text { Q42 }\end{array}$ \\
\hline \multicolumn{11}{|l|}{ Sign Test } \\
\hline Positive Differences & 10 & 12 & 7 & 40 & 11 & 6 & 4 & 6 & 6 & 13 \\
\hline Negative Differences & 6 & 7 & 12 & 6 & 8 & 8 & 6 & 10 & 1 & 0 \\
\hline Ties & 40 & 37 & 37 & 40 & 37 & 42 & 46 & 40 & 49 & 43 \\
\hline Total & 56 & 56 & 56 & 56 & 56 & 56 & 56 & 56 & 56 & 56 \\
\hline Exact Sig. (2-tailed) & ,454 &, 359 &, 359 &, 424 & ,648 & ,791 &, 754 &, 454 &, 125 &, $000^{*}$ \\
\hline \multicolumn{11}{|l|}{ Wilcoxon Signed Ranks Test } \\
\hline Z & $-1,147$ &,- 853 &,- 693 & $-1,488$ &,- 805 &,- 295 &,- 277 &,- 938 & $-1,983$ & $-3,500$ \\
\hline Asymp. Sig. (2-tailed) &, 251 &, 394 & 488 & ,137 &, 421 &, 768 & ,782 & ,348 &, $047^{* *}$ &, $000^{*}$ \\
\hline Exact Sig. (2-tailed) &, 363 &, 526 &, 574 &, 166 &, 440 & 831 & 1,000 &, 412 &, $078^{* * *}$ &, $000^{*}$ \\
\hline \multicolumn{11}{|l|}{ Marginal Homogeneity Test } \\
\hline Distinct Values & 4 & 3 & 5 & 5 & 5 & 5 & 4 & 4 & 4 & 3 \\
\hline Off-Diagonal Cases & 16 & 19 & 19 & 14 & 19 & 14 & 10 & 16 & 7 & 13 \\
\hline Observed MH Statistic & 73,0 & 87,0 & 79,0 & 58,0 & 73,0 & 59,0 & 44,0 & 66,0 & 34,0 & 65,0 \\
\hline Mean MH Statistic & 70,5 & 85,0 & 80,5 & 54,0 & 70,5 & 59,0 & 43,5 & 67,5 & 29,0 & 58,0 \\
\hline Std. Deviation of MH Statistic & 2,179 & 2,345 & 2,872 & 2,828 & 3,571 & 3,082 & 2,500 & 3,041 & 2,646 & 2,000 \\
\hline Std. MH Statistic & 1,147 &, 853 &,- 522 & 1,414 & ,700 &, 000 & ,200 &,- 493 & 1,890 & 3,500 \\
\hline Assymp. Sig. (2-tailed) &, 251 &, 394 &, 602 &, 157 & ,484 & 1,000 &, 841 &, 622 &, $059^{* * *}$ &, $000^{*}$ \\
\hline Exact Sig. (2-tailed) &, 363 &, 526 & ,735 & ,220 & ,582 & 1,000 & 1,000 & ,762 &, $078^{* * *}$ &, $000^{*}$ \\
\hline
\end{tabular}

* significante em $1 \% \quad * *$ significante em $5 \%$

*** significante em $10 \%$ 
Na Tabela 6, pode-se observar que as respostas para as assertivas 24 e 43 possuem diferença estatisticamente significante em um nível de $5 \%$ em todos os testes (Exact Sig. 2-tailed $=0.049$ para o Teste de Homogeneidade Marginal). As respostas das assertivas 28 e 48 apresentam diferença estatisticamente significante em um ní- vel de 5\% para todos os testes (Exact Sig. 2-tailed $=0.022$ para o teste de homogeneidade marginal). As respostas para as assertivas 29 e 46 apresentam diferença estatisticamente significante em um nível de $10 \%$ com o Teste de Wilcoxon e de Homogeneidade Marginal (Exact Sig. 2-tailed $=0.092$ para ambos os testes).

Tabela 6 Testes não paramétricos - Relação entre orientador e pesquisador \& relação com os pares

\begin{tabular}{|c|c|c|c|c|c|c|c|c|c|}
\hline \multirow[b]{2}{*}{ Paired Questions } & \multicolumn{5}{|c|}{$\begin{array}{l}\text { B. Aspectos éticos relacionados à orientação de alunos e na } \\
\text { relação entre orientador e pesquisador }\end{array}$} & \multicolumn{4}{|c|}{$\begin{array}{l}\text { C. Aspectos éticos relacionados à relação com } \\
\text { os pares e o desenvolvimento de pesquisas } \\
\text { conjuntas e a disseminação de resultados }\end{array}$} \\
\hline & $\begin{array}{c}\text { Q24 \& } \\
\text { Q43 }\end{array}$ & $\begin{array}{c}\text { Q25 \& } \\
\text { Q44 }\end{array}$ & $\begin{array}{l}\text { Q26 \& } \\
\text { Q45 }\end{array}$ & $\begin{array}{l}\text { Q27 \& } \\
\text { Q47 }\end{array}$ & $\begin{array}{l}\text { Q28 \& } \\
\text { Q48 }\end{array}$ & $\begin{array}{c}\text { Q29 } \\
\& \text { Q46 }\end{array}$ & $\begin{array}{l}\text { Q30 \& } \\
\text { Q49 }\end{array}$ & $\begin{array}{l}\text { Q31 \& } \\
\text { Q50 }\end{array}$ & $\begin{array}{l}\text { Q32 \& } \\
\text { Q51 }\end{array}$ \\
\hline \multicolumn{10}{|l|}{ Sign Test } \\
\hline Positive Differences & 18 & 16 & 14 & 10 & 6 & 2 & 5 & 8 & 10 \\
\hline Negative Differences & 7 & 16 & 13 & 5 & 17 & 8 & 11 & 9 & 9 \\
\hline Ties & 31 & 24 & 29 & 41 & 33 & 46 & 40 & 39 & 37 \\
\hline Total & 56 & 56 & 56 & 56 & 56 & 56 & 56 & 56 & 56 \\
\hline Exact Sig. (2-tailed) &, $043^{* *}$ & 1,000 & 1,000 &, 302 &, $035^{* *}$ & , 109 &, 210 & 1,000 & 1,000 \\
\hline \multicolumn{10}{|l|}{ Wilcoxon Signed Ranks Test } \\
\hline Z & $-2,260$ &,- 457 &,- 365 & $-1,537$ & $-2,415$ & $-1,941$ & $-1,606$ &, 000 &,- 599 \\
\hline Asymp. Sig. (2-tailed) &, $024^{* *}$ & ,648 &, 715 &, 124 &, $016^{* *}$ &, $052^{* * *}$ &, 108 & 1,000 &, 549 \\
\hline Exact Sig. (2-tailed) &, $021^{* *}$ & ,648 &, 856 &, 174 &, $022^{* *}$ &, $092^{* * *}$ &, 168 & 1,000 &, 563 \\
\hline \multicolumn{10}{|l|}{ Marginal Homogeneity Test } \\
\hline Distinct Values & 5 & 5 & 5 & 4 & 5 & 3 & 5 & 5 & 5 \\
\hline Off-Diagonal Cases & 25 & 32 & 27 & 15 & 23 & 10 & 16 & 17 & 19 \\
\hline Observed MH Statistic & 109,0 & 110,0 & 114,0 & 67,0 & 88,0 & 38,0 & 60,0 & 69,0 & 78,0 \\
\hline Mean MH Statistic & 99,5 & 112,0 & 112,0 & 62,5 & 95,0 & 41,5 & 63,5 & 68,5 & 76,0 \\
\hline Std. Deviation of MH Statistic & 4,610 & 4,183 & 3,240 & 2,872 & 2,915 & 1,803 & 2,179 & 2,500 & 3,000 \\
\hline Std. MH Statistic & 2,061 &,- 478 &, 617 & 1,567 & $-2,401$ & $-1,941$ & $-1,606$ &, 200 &, 667 \\
\hline Asymp. Sig. (2-tailed) &, $039^{* *}$ &, 633 &, 537 &, 117 &, $016^{* *}$ &, $052^{* * *}$ &, 108 &, 841 &, 505 \\
\hline Exact Sig. (2-tailed) &, $049 * *$ &, 726 & ,662 & ,169 &, $022^{* *}$ &, $092^{* * *}$ & , 168 & 1,000 & ,626 \\
\hline
\end{tabular}

* significante em $1 \% \quad * *$ significante em $5 \%$

*** significante em $10 \%$

Em síntese, os resultados das Tabelas 5 e 6 mostram que há diferenças estatisticamente significantes entre algumas assertivas pareadas, sugerindo haver diferenças entre a crença dos acadêmicos, em nível de importância, e a prática na condução das pesquisas. Dessa forma, os resultados obtidos encontram-se em conformidade com o pensamento de Foucault, resumido por Diáz (2005). Na sequência, apresentam-se essas assertivas segregadas em suas dimensões:
Dimensão A: Aspectos éticos relacionados ao processo de pesquisa científica: Assertiva 22: Manter-se fiel aos dados / informações coletadas e 41: Eu não interfiro nos dados/ informações coletados a minha conveniência. A diferença entre essas respostas pode sugerir que, apesar de a maioria dos respondentes acreditarem que esse seja um valor importante, os que o praticam são em menor número. O mesmo ocorre com a assertiva 23: Manter a 
fidedignidade dos resultados obtidos independentemente de contrariarem a hipótese levantada e 42: Eu me mantenho imparcial diante dos resultados obtidos, sugere o mesmo.

Dimensão B: Aspectos éticos relacionados à orientação de alunos e na relação entre orientador e pesquisador: Assertiva 24: Estabelecimento de um processo transparente de atribuição de orientandos aos seus respectivos orientadores \& assertiva 43: No processo de atribuição de orientandos aos orientadores eu não interfiro cooptando aqueles que eu identifico como os de maior potencial técnico e científico. Essa diferença pode sugerir que, apesar de a maioria dos respondentes acreditarem que esse seja um valor importante, aqueles que o praticam são em menor número. Entretanto, as assertivas 28: estabelecer com o orientando os critérios que definem a ordem de autoria e co- autoria dos artigos gerados pela pesquisa realizada pelo aluno e 48: eu deixo claro para os meus orientados os critérios que definem a autoria e co-autoria dos artigos gerados pela pesquisa realizada, sugerem que apesar de a maioria dos respondentes praticarem, aqueles que acreditam nesse valor são menos frequentes.

Dimensão C: Aspectos éticos relacionados à relação com os pares e o desenvolvimento de pesquisas conjuntas e a disseminação de resultados: Assertiva 29: Manter-se fiel às ideias de autores consultados não invertendo frases ou substituindo palavras por seus sinônimos e 46: Informar a fonte consultada seja por citação literal ou paráfrase, também, sugere que apesar de a maioria dos respondentes praticarem, aqueles que acreditam nesse valor são em menor número.

\section{CONSIDERAÇÕES FINAIS}

Este estudo abordou a questão da ética na pesquisa científica em contabilidade buscando, especificamente, identificar as questões éticas que envolvem a pesquisa científica segundo a crença dos que a conduzem, em nível de importância e em três dimensões: a) processo de pesquisa; $b$ ) orientação de alunos e c) relação com os seus pares e disseminação do conhecimento. Além disso, buscou-se identificar a prática (práxis) do pesquisador em relação a essas questões, cuja análise conjunta desses resultados permitiu identificar divergências entre a crença e a prática.

Para tanto, está fundamentado no pensamento de Foucault (1984) segundo o qual o comportamento ético do indivíduo recai muito mais nas formas de subjetivação e nas práticas do ser, do que na observância de um código de ética formalizado.

As assertivas que compuseram o instrumento de coleta de dados podem ser consideradas como um código de ética informalmente estabelecido para o processo de pesquisa, visto terem sido extraídas de referências re- levantes sobre o tema. Os resultados obtidos revelaram que todas as assertivas são consideradas importantes, segundo a percepção dos respondentes, representando uma crença consensual, exceto pelas assertivas 25 e 26 .

Todavia, a análise pareada das diferenças de respostas entre a importância de um aspecto ético e a sua prática, mostrou que nem sempre a crença revelada está de acordo com a prática adotada. Esses resultados sugerem, portanto, que alguns valores que são considerados importantes, não são praticados na mesma intensidade; enquanto outros valores considerados como de extrema importância, são intensamente praticados. Logo, não se pode ignorar as diferenças existentes, o que está alinhado com as ideias de Foucault sobre a moral, ou seja, a moral, também, pode ser entendida como um comportamento real dos indivíduos em relação às regras e valores que lhes são propostos, o que implica a forma com que seguem mais ou menos um código de ética, seja ele formalmente estabelecido ou não. 
Vale ressaltar que, ao se realizar esta pesquisa, não se pretendeu, sobremaneira, fazer qualquer julgamento de valor sobre a conduta dos pesquisadores, já que, conforme Foucault (1984), a relação ética é muito mais uma relação do indivíduo consigo mesmo, do que com a mera observância de um código. Assim, os resultados revelam como os acadêmcios agem na realização de suas pesquisas, na orientação de seus alunos e na relação com os seus pares e, ainda, na disseminação do conhecimento gerado, numa relação consigo mesmo.

Nesse ponto, cabe citar a observação de Agostini (2011, p.98) de que, "embora possa parecer que a visão que desenvolvemos acerca de nós e do mundo seja estritamente particular, na realidade, é essa visão que determina em grande medida a maneira pela qual nos relacionamos com os outros". Dessa forma, entende-se que as nossas crenças podem e devem ser sempre repensadas, refletidas, reavaliadas, recaindo "nas formas de subjetivação e nas práticas do ser" (Foucault, 1984, p.36), pois "existem alguns deveres que, como cidadãos, devemos cumprir para o bom funcionamento da sociedade, deveres estes que também garantem a manutenção dos nossos direitos" (AGOSTINI, 2011, p.98).

Nesse sentido, cabem algumas considerações adicionais. Primeiramente, em se tratando de uma pesquisa direcionada a acadêmicos pesquisadores, era de se esperar um censo, ou seja, que todos os consultados respondessem, já que a atividade de pesquisa é para eles a razão de sua profissão e uma de suas principais responsabilidades para com a sociedade. No entanto, apenas 25,69\% dos pesquisadores responderam, o que, apesar de não invalidar o estudo, já que a amostra é significativa (HILL \& HILL, 2008), não deixa de ser decepcionante. Cabe, aqui, portanto, a seguinte questão: até que ponto os acadêmicos pesquisadores se importam, realmente, em colaborar com a produção do conhecimento (pesquisas) quando lhes é solicitado?
Um segundo aspecto que merece uma reflexão mais aprofundada, refere-se à tendência da pesquisa na área de contabilidade, notadamente no campo da contabilidade gerencial, que está convergindo para abordagens não tradicionais, a exemplo da pesquisa intervencionista, na qual a interação com os participantes deve exigir protocolos de relacionamento mais rigorosos, já que, nesse caso, o pesquisador intervém na prática cotidiana do ambiente pesquisado. Nesse sentido, poderão ser admitidas diferenças entre o acordado e o praticado?

Outro aspecto ainda a ser mencionado trata das pesquisas no campo da neurociência aplicada à contabilidade (Neuroaccounting) nas quais, ao se pesquisarem variações de comportamentos em processos decisórios, se realizam experimentos em voluntários que, embora sejam considerados não invasivos, uma vez que são realizados por meio de equipamentos eletrônicos de uso externo, poder-se-ia dispensar a consulta aos Comitês de Éticas, formalmente estabelecidos nas Universidades?

Essas são apenas algumas questões que devem suscitar a preocupação da comunidade acadêmica, pois, evidentemente, neste estudo, não foram inteiramente cobertos todos os problemas éticos que podem surgir em um processo de investigação científica, mas que são, sem dúvida, relevantes, segundo a literatura sobre o assunto e a experiência dos autores.

Por fim, não é pretensão deste estudo estabelecer nenhuma norma de conduta para a comunidade de pesquisadores na área de contabilidade, mas, apenas, expor algumas situações que merecem maior reflexão por parte dela; mas isso também não impede de se sugerir uma agenda para o tema. Nesse sentido, entende-se ser conveniente que a ANPCONT, por meio de uma consulta aos pares, elaborasse um guia de conduta; é fato que a formalização desses procedimentos facilita a sua divulgação e conhecimento pelos indivíduos e permi- 
te, ainda, sanções formais aos transgressores, embora não garanta a sua observância. Da mesma forma, sugere-se que os programas de pós-graduação introduzam em seus currículos o estudo da ética numa abordagem filosófica e não apenas um estudo deontológico.

\section{Referências}

AGOSTINI, C. S. Platão e Aristóteles. Mente Cérebro \& Filosofia, v.1, p. 98, 2011

ALVES, J. S.; LISBOA, N., P.; WEFFORT, E. F. J.; ANTUNES, M. T. P. Um estudo empírico sobre a importância do código de ética profissional para o contabilista. Revista de Contabilidade e Finanças da Universidade de São Paulo, n.18, no. spe. p. 58-68, 2007. ARMSTRONG, M. Ethics and professionalism in accounting education: a sample course. Journal of Accounting Education, v.11, n.1, p. 77-92, 1993. APPOLINÁRIO, F. Dicionário de Metodologia Científica: um guia prático para a produção do conhecimento científico. São Paulo: Atlas, 2007.

BEUREN, I. M. Como elaborar trabalhos monográficos em contabilidade. 3. ed. São Paulo: Atlas, 2008. BOILLOT, H. Petit Larousse de la Philosophie. Paris: Larousse, 2007.

BOOTH, W. C.; COLOMB, G. G.; WILLIAMS, J. M. The craft of research. 3rd edition. Chicago: University Of Chicago Press, 2008.

BORGES, E.; MEDEIROS, C. Comprometimento e ética profissional: um estudo de suas relações junto aos contabilistas. Revista de Contabilidade e Finanças da Universidade de São Paulo, v.44, p.60-71, 2007. BROWN, D.; MENDENHALL, S.; KHAMER, J. Business ethics programs: is internal audit playing a proactive role? Internal Auditing, v. 18, n.4, p. 28-32, 2003. CARDOSO, R. L. Competências do contador: um estudo empírico. São Paulo, 2006. Tese (Doutorado em Contabilidade) - Faculdade de Economia, Administração e Contabilidade. São Paulo: Universidade de São Paulo, 2006.

CARDOSO, J. L.; SOUZA, M. A de.; ALMEIDA, L. B. Perfil do contador na atualidade. BASE - Revista de Administração da Unisinos, v. 3, n.3, 275-284, 2006. CASTRO, E. Vocabulário de Foucault. Belo Horizonte: Autêntica Editora, 2009.

COHEN, J.; PANT, L.W.; SHARP, D.J. An international comparison of moral constructs underlying auditors' ethical judgments. Research on Accounting Ethics, v. 1, p. 97-126, 1995.

COLLIS J.; HUSSEY, R. Business Research: A Practical Guide for Undergraduate and Postgraduate Students. 3rd edition. London: Palgrave Macmillan, 2009.

CRESWELL, J. W. Research design: qualitative, quantitative and mixed methods approaches. 2rd edition . London: Sage Publications Inc., 2003.

DIÁZ, Esther. La filosofía de Michel Foucault. Buenos Aires: Editorial Biblos, 2005.

DIEHL, A. A; TATIN, D. C. Pesquisa em ciências sociais aplicadas. São Paulo: Prentice Hall, 2004.

FINN, D.W.; CHONKO, L.B.; HUNT, S.D. Ethical problems in public accounting: the view from the top.
Journal of Business Ethics, v. 7, n. 8, p. 605-15, 1988. FOUCAULT, M. Histoire de la sexualité II: Lúsage des plaisirs. Paris: Éditions Gallimard, 1984. GREEN, S. B; SALKING, N. J; AKEY, T. M. Using SPSS for Windows - analyzing and understanding data, $2^{\text {nd }}$ edition, New Jersey: Prentice-Hall, 2000.

GOODWIN, J.; GOODWIN, D.; FIEDLER, B. The influence of culture on accountants' ethical decision making in Singapore and Australia. Accounting Research Journal, v. 13, n. 2, p. 24-38, 2000.

GREEN, S.; WEBER, J. Influencing ethical development: exposing students to the AICPA code of conduct. Journal of Business Ethics, v. 16, n.8, p. 777-90, 1997.

GUL, F.A.; NG, A.Y.; TONG, M.W. Chinese auditors' ethical behavior in an audit conflict situation. Journal of Business Ethics, v. 42, n.4, 379-392, 2003.

GUSTAFSSON, B.; RYDEN, L.; TIBELL, G.;

WALLENSTEEN, P. Focus On: The Uppsala Code of Ethics for Scientists. Journal of Peace Research, v. 21, n.4, p. 311-316, 1984.

HILL, M. M.; HILL, A. Investigação por questionário. Lisboa: Edições Sílabo, 2008.

HILTEBEITEL, K.M.; JONES, S.K. An assessment of ethics instruction in accounting education. Journal of Business Ethics, v. 1, n.1, p. 37-46, 1992.

HO, Y.; LIN, C. Cultural values and cognitive moral development of accounting ethics: a cross-cultural study. Social Behavior and Personality, v. 36, n.7, p. 883-892, 2008.

JEFFREY, C.; WEATHERHOLT, N. Ethical development, professional commitment, and rule observance attitudes: a study of CPAs and corporate accountants. Behavioral Research in Accounting, v. 8, n.1, p. 8-31, 1996.

LALANDE, A. Vocabulário técnico e crítico da filosofia. Porto: Rês, 1985.

LEITE, A. P. R.; TACCONI, M. F. F. S.; EL-AOAUR, W. A.; MOL, A. L. R.; ALEXANDRE, M. L. Ética na Pesquisa em Administração - Reflexões junto aos Pesquisadores da Universidade Federal do Rio Grande do Norte. In: ENCONTRO NACIONAL DA ASSOCIAÇÃO NACIONAL DE PÓS-GRADUAÇÃO E PESQUISA EM ADMINISTRAÇÃO, 33., 2009, Rio de Janeiro. Anais... Anpad, Rio de Janeiro, RJ, Brasil, 2009. LEITE, A. P. R; ALEXANDRE, M. L.; TACCONI, M. F. F. S.; ARAUJO, M. V. P. Percepções e Reflexões de Pesquisadores - Uma Abordagem sobre Ética na Pesquisa. In: ENCONTRO NACIONAL DA ASSOCIAÇÃO NACIONAL DE PÓS-GRADUAÇÃO E PESQUISA EM ADMINISTRAÇÃO, 34., 2010, Rio de Janeiro. Anais... Anpad, Rio de Janeiro, RJ, Brasil, 2010. LEUNG, P.; COOPER, B. J. Ethics in accountancy: a classroom experience. Accounting Education, v. 3, n.1, p. 19-33, 1994. 
MARCONDES, D. Textos básicos de ética: de Platão a Foucault. Rio de Janeiro: Zahar, 2009.

MELE, D. Ethical education in accounting: integrating rules, values and virtue. Journal of Business Ethics, v. 57, n.1, p. 97-109, 2005.

MEHTA, C. R; PATEL, N. R. Exact Tests. Chicago: SPSS, 2008.

MINTZ, S.M. Virtue ethics and accounting education. Issues in Accounting Education, v. 10, n. 2, p. 247-67, 1995. MIYAZAKI, A; TAYLOR, K. Researcher Interaction Biases and Business Ethics Research: Respondent Reactions to Researcher Characteristics. Journal of Business Ethics, v. 81, n. 4, p. 779-795, 2008.

NEEDLES Jr., B. E. The International Association for Accounting Education and Research (IAAER): The Code of Ethics for Accounting Educators. Accounting Education, v.17, p.81-82, 2008.

PAIVA, V. L. M. de O. Reflexões sobre ética e pesquisa. Revista Brasileira de Lingüística Aplicada, v. 5, n. 1, p. 43-61, 2005.

PELEIAS, I. R.; WAHLMANN, G. C.; PARISI, C.; ANTUNES, 2M. T. P. A. Revista de Administração e Inovação, v. 7, n.1, p. 158-177, 2010.

PIRES, C. B.; OTT, E.; DAMACENA. C. "GuardaLivros"ou "Parceiros de Negócios'? Uma análise do perfil profissional requerido pelo mercado de trabalho para contadores na região metropolitana de Porto Alegre. Revista de Contabilidade Vista \& Revista. Universidade Federal de Minas Gerais, v. 20, n.3, p. 157-187, 2009. SANTOS, E.; SİLVA NETO, N. A. A ética no uso dos testes psicológicos, na informação e na pesquisa. São Paulo: Casa do Psicólogo, 2000.

SHAUB, M. An analysis of the association of traditional demographic variables with the moral reasoning of auditing students and auditors. Journal of Accounting
Education, v.12, n.1, p. 1-26, 1994.

SHEARER, T. Ethics and accountability: from the foritself to the for-the-other. Accounting, Organizations and Society, v. 27, n. 6, p. 541-573, 2002.

STENING, B. W; SKUBIK, D. W. Do International Management Researchers Need a Code of Ethics? Management International Review (MIR), v. 47, n.1, p. 103-126, 2007.

SCHOLZE, S. H. C. Code of Conduct for scientists. Division of Ethics of Science and Technology. United Nations Educational, Scientific and Cultural Organization, 2001. UNESCO. Disponível em http:// portal.unesco.org/ci/en/files/19987/11272282261 Scholze PPT.pdf/Scholze \%2 BPPT.pdf. Acesso em: 9 de novembro, 2010,

ST PIERRE, K.; NELSON, E; GABBIN, A. A study of the ethical development of accounting majors in relation to other business and non-business disciplines. The Accounting Educators' Journal, v. 3, n. 1, p. 23-35, 1990.

TSUI, J.; GUL, F. Auditors' behavior in an audit conflict situation: a research note on the role of locus of control and ethical reasoning. Accounting, Organizations and Society, v. 21, n.1, p. 41-51, 1996.

THORNE, L.; MASSEY, D.; MAGNAN, M. Institutional context and auditors' moral reasoning: a Canada-USA comparison. Journal of Business Ethics, v. 43, n. 4, p. 305-21, 2003.

UYSAL, Ö, Ö. Business Ethics Research with an Accounting Focus: A Bibliometric Analysis from 1988 to 2007. Journal of Business Ethics, v.93, p. 137-160, 2009.

YAYLA, H. E.; DEMIR, H. Testing Parrhesia in accouting profession. In: ANNUAL EUROPEAN ACCOUTING ASSOCIATION CONGRESS, 32., 2009, Tampere. Anais... EAA, Tampere, Finland, 2009. 